\title{
Laparoscopic Hepatic Posterior Sectionectomy: A Hand-assisted Approach
}

\author{
Paulo Herman, MD, PhD, Jaime Arthur Pirola Krüger, MD, Marcos Vinícius Perini, MD, PhD, \\ Fabrício Ferreira Coelho, MD, PhD, and Renato Micelli Lupinacci, MD
}

Department of Gastroenterology, Liver Surgery Unit, University of Sao Paulo, Sao Paulo, Brazil

\begin{abstract}
Background. Hepatic resection remains a challenging procedure in laparoscopy, requiring trained surgical teams and specialized centers. ${ }^{1-3}$ Operating on the posterior segments of the liver brings additional concerns, such as vascular control, right liver mobilization from the retroperitoneum and diaphragm, and a large transection area. ${ }^{1,3-6}$ Here we present a case of a hepatitis B-positive 42-year-old woman with a neoplastic nodule on the right posterior section of the noncirrhotic liver.

Methods. Pneumoperitoneum was made through a hand port, and three additional trocars were placed. Intrahepatic glissonian pedicle control was achieved after liver mobilization. Parenchymal transection was performed through the demarcation line between the anterior well vascularized and the posterior ischemic right segments of the liver. All surgical steps were performed with hand assistance.

Results. Operative time was $210 \mathrm{~min}$, and estimated blood loss was $300 \mathrm{ml}$. Postoperative was uneventful. The patient was discharged on the fourth postoperative day. Histological evaluation confirmed the diagnosis of a welldifferentiated hepatocellular carcinoma. The patient was free of disease after 18 months of follow-up.

Discussion. Our video shows a standardized operative strategy in which the hand assistance plays important role. Posterosuperior segments of the liver are still less often approached by laparoscopic surgery as a result of its
\end{abstract}

Electronic supplementary material The online version of this article (doi:10.1245/s10434-012-2750-3) contains supplementary material, which is available to authorized users.

(C) Society of Surgical Oncology 2012

First Received: 28 August 2012;

Published Online: 16 December 2012

J. A. P. Krüger, MD

e-mail: jaimearthur@yahoo.com limitations on visualization, mobilization, pedicle control, and parenchymal transection. ${ }^{1,3,6}$ Hand assistance helps solve these issues, making assisted resection easier than a purely laparoscopic approach and more advantageous over the open technique, providing the benefits of laparoscopy without compromising oncological safety. ${ }^{7}$

\section{REFERENCES}

1. Nguyen KT, Gamblin TC, Geller DA. World review of laparoscopic liver resection-2,804 patients. Ann Surg. 2009;250:83141.

2. Buell JF, Thomas MT, Rudich S, et al. Experience with more than 500 minimally invasive hepatic procedures. Ann Surg. 2008;248: 475-86.

3. Koffron AJ, Auffenberg G, Kung R, et al. Evaluation of 300 minimally invasive liver resections at a single institution: less is more. Ann Surg. 2007;246:385-92.

4. Yoon YS, Han HS, Choi YS, et al. Total laparoscopic right posterior sectionectomy for hepatocellular carcinoma. J Laparoendosc Adv Surg Tech A. 2006;16:274-7.

5. Torzilli G, Donadon M, Marconi M, et al. Systematic extended right posterior sectionectomy: a safe and effective alternative to right hepatectomy. Ann Surg. 2008;247:603-11.

6. Cho JY, Han HS, Yoon YS, Shin SH. Feasibility of laparoscopic liver resection for tumors located in the posterosuperior segments of the liver, with a special reference to overcoming current limitations on tumor location. Surgery. 2008;144:32-8.

7. Gumbs AA, Gayet B. Video: the lateral laparoscopic approach to lesions in the posterior segments. J Gastrointest Surg. 2008;12: 1154 . 